\title{
Temperature Trend Detection in Upper Indus Basin by Using Mann-Kendall Test
}

\author{
Ateeq Ur Rauf ${ }^{1}$, Muhammad Salman Rafi ${ }^{2}$, Irshad $\mathrm{Ali}^{2}$, Uzair Wali Muhammad ${ }^{2}$ \\ ${ }^{1}$ Civil Engineering Department, University of Engineering and Technology Taxila, 47080, Pakistan and Civil Engineering Department, \\ University of Engineering and Technology Peshawar, 25000, Pakistan
}

${ }^{2}$ Civil Engineering Department, University of Engineering and Technology Peshawar, Bannu Campus, 28100, Pakistan

\begin{tabular}{l} 
A R T I C L E I N F O \\
\hline Article history: \\
Received: 21 June, 2016 \\
Accepted: 25 August, 2016 \\
Online: 25 October, 2016 \\
\hline Keywords: \\
Trend Detection \\
Global Warming \\
Climate Change \\
Mann-Kendall Test \\
HKH Region \\
Monthly Trends \\
Seasonal Trends \\
Glacial Melting \\
Meteorology
\end{tabular}

A B S T R A C T
Global warming and Climate change are commonly acknowledged as the most noteworthy
environmental quandary the world is undergoing today. Contemporary studies have
revealed that the Earth's surface air temperature has augmented by $0.6^{\circ} \mathrm{C}-0.8^{\circ} \mathrm{C}$ in the
course of the $20^{\text {th }}$ century, together with alterations in the hydrological cycle. This study
focuses on detecting trends in seasonal temperature for the five selected stations in the
Upper Indus Basin. The Mann-Kendall test was run at $5 \%$ significance level on time series
data for each of the five stations during the time period, 1985 to 2014. The Standard Test
Statistic (Z, indicates the presence of trend and whether it is increasing or decreasing. The
analysis showed an increasing trend in mean monthly temperature at Astore, Gilgit and
Gupiz in March and a decreasing trend for Astore, Drosh, Gilgit and Skardu in September.
Gilgit and Gupiz showed unexpected increasing trend in October. This study concludes that
the temperature starts increasing in March and stays elevated till the month of June and
starts rising again in October thus resulting in expansion of summer season and prolonged
glacial melting.

\section{Introduction}

\subsection{General}

Temperature is a vital component of climate and vicissitudes in its pattern can clout ecosystems, plants, animals, human health and ecological diversity. Recent studies have shown that the Earth's surface air temperature has increased by $0.6^{\circ} \mathrm{C}-0.8^{\circ} \mathrm{C}$ during the 20 th century, along with changes in the hydrological cycle [1]. Scientific evidence shows that climate change has begun to manifest itself, globally, in the form of increased downpours and storms, rising temperature and sea level, retreating glaciers, etc [2]. An escalation in temperature can upshot heat wave incidents and trigger illness and death in predisposed populaces. An upsurge in Earth's temperature leads to more evaporation and cloud development to take place, which in turn, proliferates precipitation [3].

${ }^{*}$ Corresponding Author: Ateeq Ur Rauf, University of Engineering and Technology Taxila, 47080, Pakistan

Email: bhaisahib13@hotmail.com
Pakistan is markedly susceptible to climate change for the reason that it has generally a volatile climate. It rests in a world region where the temperature escalations are presumed to be higher than the global averages. Its rivers are primarily supplied by the Hindu Kush-Karakoram-Himalaya (HKH) glaciers which are envisaged to be melting and retreating swiftly due to global warming [4]. Its economy is chiefly agrarian and consequently highly climate susceptible; so the country confronts increasingly larger risks of inconsistency in monsoon rains, large floods and protracted droughts [4]. Under the influence of all these factors the water security and the food security of the country are under serious threat. This study focuses on trend detection in seasonal temperature for five selected sub basins of Upper Indus Basin (UIB). Since flows influence of all these factors the water security and the food security of the country are under serious threat [13]. This study on trend detection in seasonal temperature for five selected sub basins of Upper Indus Basin (UIB). Since flows in upper Indus River, within KP, are directly affected by the waters- 


\section{A.U. Rauf et al. / Advances in Science, Technology and Engineering Systems Journal Vol. 1, No. 4, 5-13 (2016)}

hed of these five sub basins. Using data from the Pakistan Metrological Department, study identifies the UIB temperature patterns from 1985 to 2014 .

\subsection{Recent Related Research}

1- In view of a study conducted by [6] assessed the trend pattern of stream flow, rainfall, temperature and evaporation in River Kaduna. The difference in evaporation amount between 1980 1990 and 1991-2001 was $81 \mathrm{~mm} /$ day; this implies that there exists slight evaporation within the catchment area. Also, the difference in rainfall amount between 1980 -1990 and 19912012 was $14,619 \mathrm{~mm}$. This implies that there are lots of climate change activities in the whole catchment area. Thus, the study confirmed that the increase in temperature causes more intense evaporation via relative humidity.

2- In a study conducted by [7] it was identified whether statistically significant changes in the spatio-temporal trends in the maximum and minimum temperatures and precipitation (amount and distribution) at different time scales occurred under climate change or not, in North Korea. They concluded that there are significant differences in meteorological elements, and particular locations and urbanized areas were affected by global warming.

3- In conclusion of a study led by [8] it was stated that primarily winter temperatures were increasing with increases also in spring and fall. They did not find clear increasing or decreasing trends in summer, though they found evidence of longer durations of periods with hot days. The analyses of datasets reveal clear temperature increases in summer, particularly for minimum temperatures and significant changes (decreasing) in precipitation in the summer and fall for nearly a quarter to a third of the country, depending on the season.

4- In a study led by [9] upon the possible impacts of climate change on the water resources of the Kunhar River basin, Pakistan. The overall conclusion of the study was that the Kunhar basin is likely to face more floods and droughts in the future due to the projected increase in high flows and decrease in low flows.

5- The study conducted by [10] for annual precipitation and mean annual temperature in the state of Kentucky indicates that, over the period 1950-2010, both of these variables generally did not exhibit any statistically significant trends with respect to time. The relatively small number of significant trends detected. However all were in the positive direction, and all were associated with weather stations very close to the borders of the state.

6- According to a study conducted by [11] the mean minimum annual temperature has declined in most of the region of Upper Indus Basin for the period (1961 to 2011). Maximum and mean temperature has increased with increase in elevation while the minimum temperature and precipitation has more decreasing rate in higher mountainous catchments.

7- A report summarized by [12] about the potential future climate and hydrologic conditions based on the best available datasets and data development methodologies, its characterization of future hydroclimate possibilities implicitly reflects several uncertainties. Trying to identify an exact climate change impact at a particular place and time remains difficult, despite advances in modeling efforts over the past half-century. U.S average temperature has increased by $1.3^{\circ} \mathrm{F}$ to $1.9^{\circ} \mathrm{F}$ since record keeping began in 1895 . Most of this increase has occurred since about 1970. The Western U.S has warmed roughly $2^{\circ} \mathrm{F}$ in the basin considered here and is projected to warm further during the 21 st century.

\subsection{Study Area}

The Indus River basin is one of the world's largest basins, having an area of approximately $970,000 \mathrm{~km}^{2}$. However, this study is cramped only to Upper Indus River Basin (UIRB) that lies between the source of Indus river and Tarbela reservoir comprising a basin area of about $175,000 \mathrm{~km}^{2}$ [13].

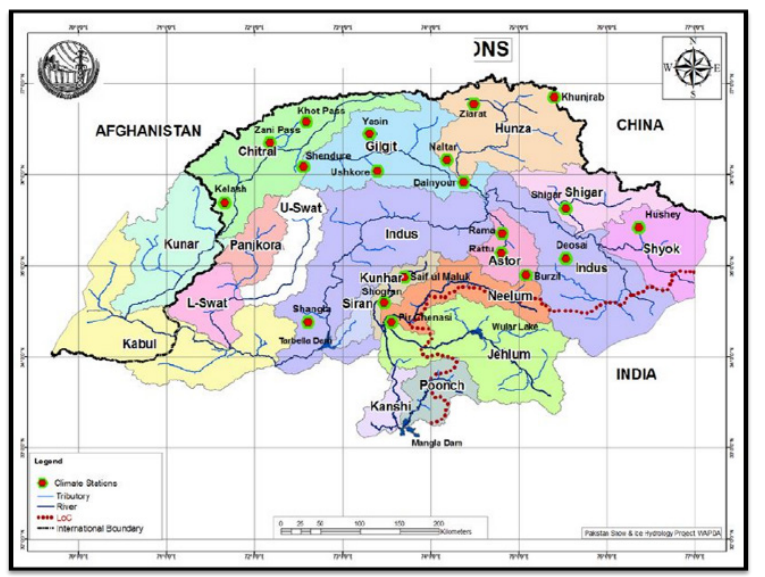

Figure 1: Climatic and River gauging stations in UIB [14]

\subsection{Hydro Meteorological Network in Study Area}

Twelve Climate stations are installed by Pakistan Meteorological Department (PMD), Islamabad, Pakistan in UIB of which eight are installed at five major sub basins.

Table 1: Particulars of five stations installed

\begin{tabular}{|c|c|c|c|c|}
\hline ID & $\begin{array}{l}\text { Station } \\
\text { Name }\end{array}$ & $\begin{array}{l}\text { Lat } \\
\left({ }^{\circ} \mathrm{N}\right)\end{array}$ & $\begin{array}{l}\text { Long } \\
\left({ }^{\circ} \mathrm{E}\right)\end{array}$ & $\begin{array}{l}\text { Elevation } \\
(\mathrm{m} \text { a.s.1. })\end{array}$ \\
\hline 1 & Astore & 35.33 & 74.90 & 2394 \\
\hline 2 & Drosh & 35.56 & 71.78 & 1465 \\
\hline 3 & Gilgit & 35.91 & 74.33 & 1460 \\
\hline 4 & Gupis & 36.01 & 73.40 & 2156 \\
\hline 5 & Skardu & 35.30 & 75.68 & 2210 \\
\hline
\end{tabular}

The maximum and minimum monthly temperature data of these five selected sub-basins was collected. The scope of this study was limited to a span of 30 years i.e., from 1985-2014.

\section{Methods \& Methodology}

\subsection{Trend Analysis}

Trend analysis can be defined as the use of an empirical approach to quantify and explain changes in a system over a 
period of time. The purpose of trend testing is to determine if the values of a random variable generally increase (or decrease) over some period of time in statistical terms.

\subsection{Temperature Trends}

The continuous increase or decrease in temperature over longer time periods depends upon spatial locality of the region. If the trend shows that the temperature is increasing than this means that the trend is positive, similarly if the trend shows that the temperature is decreasing than the trend is considered to be negative.

\subsection{Methods for Trend Detection}

Two major tests are used for the trend detection.

$$
\begin{gathered}
\text { i. } \quad \text { Parametric Trend Tests } \\
\text { ii. Non-Parametric Trend Tests }
\end{gathered}
$$

\subsubsection{Parametric Trend Tests}

Parametric tests assume that the time series data and the errors (deviations from the trend) follow a particular distribution (usually normal distribution). Parametric tests are generally more powerful that non-parametric tests. For Linear and equally spaced data and cannot take into account any outliers.

There are two major parametric trend tests.
i. Regression Analysis
ii. Cumulative Deviation Test

\section{1- Regression Analysis}

This is a parametric test that assumes that the data are normally distributed. It tests for the detection of linear trend by examining the relationship between time (x) and the variable of interest (y). The regression gradient " $b$ " is estimated by:

$$
b=\frac{\sum_{i=1}^{n}\left(X_{i}-\bar{X}\right)\left(Y_{i}-\bar{Y}\right)}{\sum_{i=1}^{n}\left(X_{i}-\bar{X}\right)^{2}}
$$

and the intercept " $a$ " is estimated as:

$$
a=\bar{Y}-b \bar{X}
$$

The test statistic " $\mathrm{S}$ " is:

$$
S=\frac{b}{\sigma}
$$

where $\quad \sigma=\sqrt{\frac{12 \sum_{i=1}^{n}\left(Y_{i}-a-b X_{i}\right)}{n(n-2)\left(n^{2}-1\right)}}$

The test statistic $\mathrm{S}$ follows a Student-t distribution with $\mathrm{n}-2$ degrees of freedom under the null hypothesis. The linear regression test assumes that the data are normally distributed and that the errors (deviations from the trend) are independent and follows the same normal distribution with zero mean.

\section{2- Cumulative Deviation Test}

This method tests whether the means in two parts of a record are different (for an unknown time of change). The test assumes that the data are normally distributed. The purpose of this test is to detect a change in the mean of a time series after m observations:

$$
\begin{array}{cc}
E\left(X_{i}\right)=\mu & i=1,2,3, \ldots \ldots, m \\
E\left(X_{i}\right)=\mu+\Delta & i=m+1, m+2, \ldots \ldots, n
\end{array}
$$

where $\mu$ is the mean prior to the change and $\Delta$ is the change in the mean. The cumulative deviations from the means are calculated as:

$$
\dot{S_{0}}=0
$$

$$
S=\sum_{i=1}^{K}\left(X_{i}-\bar{X}\right) \quad k=1,2,3, \ldots \ldots, n
$$

and the rescaled adjusted partial sums are obtained by dividing the Sk values by the standard deviation:

$$
\begin{gathered}
\ddot{S_{k}}=\dot{S}_{k} / D_{x} \\
D_{X}^{2}=\sum_{i=1}^{n} \frac{\left(X_{i}-\bar{X}\right)^{2}}{n}
\end{gathered}
$$

The test statistic $\mathrm{Q}$ is:

$$
Q=\max \left|\ddot{S}_{k}\right|
$$

and is calculated for each year, with the highest value indicating the change point. A negative value of $S_{k}$ indicates that the latter part of the record has a higher mean than the earlier part and vice versa.

\subsubsection{Non-Parametric Trend Tests}

Non-parametric tests are generally distribution-free. They detect trend/change, but do not quantify the size of the trend/change. They are very useful because most hydrologic time series data are not normally distributed. Less influenced by presence of outliers.

$$
\begin{array}{cl}
\text { i. } & \text { Mann-Kendall Trend Test } \\
\text { ii. } & \text { Spearman Correlation } \\
\text { iii. } & \text { Rank-sum test }
\end{array}
$$

\section{1- Mann-Kendall Trend Test}

This method tests whether there is a trend in the time series data. It is a non-parametric test. The $\mathrm{n}$ time series values $\left(\mathrm{X}_{1}, \mathrm{X}_{2}\right.$, $\left.\mathrm{X}_{3}, \ldots, \mathrm{X}_{\mathrm{n}}\right)$ are replaced by their relative ranks $\left(\mathrm{R}_{1}, \mathrm{R}_{2}, \mathrm{R}_{3}, \ldots \ldots\right.$, $R_{n}$ ) (starting at 1 for the lowest up to $n$ ). The test statistic $S$ is:

$$
S=\sum_{i=1}^{n-1}\left[\sum_{j=i+1}^{n} \operatorname{sgn}\left(R_{j}-R_{i}\right)\right]
$$

Where

$$
\begin{aligned}
& \operatorname{sgn}(x)=1 \text { for } x>0 \\
& \operatorname{sgn}(x)=0 \text { for } x=0 \\
& \operatorname{sgn}(x)=-1 \text { for } x<0
\end{aligned}
$$

If the null hypothesis $\mathrm{Ho}$ is true, then $\mathrm{S}$ is approximately normally distributed with: 


$$
\sigma=\frac{n(n-1)(2 n+5)}{18}
$$

The z-statistic is therefore (critical test statistic values for various significance levels can be obtained from normal probability tables):

$$
z=|S| / \sigma^{0.5}
$$

A positive value of $\mathrm{S}$ indicates that there is an increasing trend and vice versa.

\section{2- Spearman's Correlation}

This is a rank-based test that determines whether the correlation between two variables is significant. In trend analysis, one variable is taken as the time itself (years) and the other as the corresponding time series data. Like the MannKendall Test, the $\mathrm{n}$ time series values are replaced by their ranks. The test statistic $\rho_{\mathrm{s}}$ is the correlation coefficient, which is obtained in the same way as the usual sample correlation coefficient, but using ranks:

$$
\begin{gathered}
\rho_{s}=S_{X Y} /\left(S_{X} S_{Y}\right)^{0.5} \\
S_{X}=\sum_{i=1}^{n}\left(X_{i}-\bar{X}\right)^{2} \\
S_{y}=\sum_{i=1}^{n}\left(Y_{i}-\bar{Y}\right)^{2} \\
S_{X Y}=\sum_{i=1}^{n}\left(X_{i}-\bar{X}\right)\left(Y_{i}-\bar{Y}\right)
\end{gathered}
$$

and xi (time), yi (variable of interest), $x$ and $y$ refer to the ranks $\left(\mathrm{x}, \mathrm{y}, \mathrm{S}_{\mathrm{x}}\right.$ and $\mathrm{S}_{\mathrm{y}}$ have the same value in a trend analysis). For large samples, the quantity $\rho \mathrm{n} 1 \mathrm{~s}-$ is approximately normally distributed with mean of 0 and variance of 1 (critical test statistic values for various significance levels can be obtained from normal probability tables).

\section{3- Rank-Sum Test}

This method tests whether the medians in two different periods are different. It is a nonparametric test. To compute the ranksum test statistic: Rank all the data, from 1 (smallest) to $\mathrm{N}$ (largest). In the case of ties (equal data values), use the average of ranks; Compute a statistic $\mathrm{S}$ as the sum of ranks of the observations in the smaller group (the number of observations in the smaller group is denoted as $\mathrm{n}$, and the number of observations in the larger group is denoted as $\mathrm{m}$ ); and compute the theoretical mean and standard deviation of $\mathrm{S}$ under $\mathrm{H}_{\mathrm{o}}$ for the entire sample

$$
\mu=\mathrm{n}(\mathrm{N}+1) / 2 \quad \sigma=[\mathrm{nm}(\mathrm{N}+1) / 12] 0.5
$$

The standardized form of the test statistic $\mathrm{Z}_{\mathrm{rs}}$ is computed as:

$$
\begin{aligned}
& Z_{\mathrm{rs}}=(\mathrm{S}-0.5-\mu) / \sigma \text { if } \mathrm{S}>\mu \\
& \mathrm{Z}_{\mathrm{rs}}=0 \quad \text { if } \quad \mathrm{S}=\mu
\end{aligned}
$$

$$
\mathrm{Z}_{\mathrm{rs}}=|\mathrm{S}+0.5-\mu| / \sigma \quad \text { if } \quad \mathrm{S}<\mu
$$

$\mathrm{Z}_{\mathrm{rs}}$ is approximately normally distributed, and the critical test statistic values for various significance levels can be obtained from normal probability tables.

\subsection{Methodology}

For data of climatic nature non-parametric trend tests are preferred. The mean monthly temperature data was climatic in nature, since temperature is a climatic parameter. Thus MannKendall Non-Parametric Trend Test was used for detection of trends in temperature in the selected sub-basins of Upper Indus River Basin.

\subsection{Mann Kendall Trend Test}

There are two advantages of using this test. First, it is a non-parametric test and does not require the data to be normally distributed. Second, the test has low sensitivity to abrupt breaks due to inhomogeneous time series. Any data reported as nondetects are included by assigning them a common value that is smaller than the smallest measured value in the data set. According to this test, the null hypothesis $\mathrm{H}_{0}$ assumes that there is no trend (the data is independent and randomly ordered) and this is tested against the alternative hypothesis $H_{1}$, which assumes that there is a trend [15].

\subsection{Computational Procedure}

The computational procedure for the Mann Kendall test considers the time series of $n$ data points where $T_{i}$ and $T_{j}$ as two subsets of data where $i=1,2,3, \ldots, n-1$ and $j=i+1, i+2, i+3, \ldots$, $\mathrm{n}$. The data values are evaluated as an ordered time series. Each data value is compared with all subsequent data values. If a data value from a later time period is higher than a data value from an earlier time period, the statistic $\mathrm{S}$ is incremented by 1 . On the other hand, if the data value from a later time period is lower than a data value sampled earlier, $\mathrm{S}$ is decremented by 1 . The net result of all such increments and decrements yields the final value of $\mathrm{S}[16]$.

\subsection{Mann-Kendall, S Statistic}

The Mann-Kendall S Statistic is computed as follows:

$$
\begin{gathered}
S=\sum_{i=1}^{n-1} \sum_{j=i+1}^{n} \operatorname{sign}\left(T_{j}-T_{i}\right) \\
\operatorname{Sign}\left(T_{j}-T_{i}\right)=\left\{\begin{array}{c}
1 \text { if } T_{j}-T_{i}>0 \\
0 \text { if } T_{j}-T_{i}=0 \\
-1 \text { if } T_{j}-T_{i}<0
\end{array}\right.
\end{gathered}
$$

where $\mathrm{T} j$ and $\mathrm{Ti}$ are the annual values in years $\mathrm{j}$ and $\mathrm{i}, \mathrm{j}>\mathrm{i}$, respectively. If $\mathrm{n}<10$, the value of $|\mathrm{S}|$ is compared directly to the theoretical distribution of $\mathrm{S}$ derived by Mann and Kendall. The two tailed test is used. At certain probability level $\mathrm{H}_{0}$ is rejected in favor of $\mathrm{H} 1$ if the absolute value of $\mathrm{S}$ equals or exceeds a specified value $S_{\alpha / 2}$, where $S_{\alpha / 2}$ is the smallest $S$ which has the probability less than $\alpha / 2$ to appear in case of no trend. A 
positive (negative) value of $\mathrm{S}$ indicates an upward (downward) trend [16].

\subsection{Variance $\left(\sigma^{2}\right)$ for the $S$-statistic}

The variance $\left(\sigma^{2}\right)$ for the S-statistic is defined by:

$$
\sigma^{2}=\frac{n(n-1)(2 n+5)-\sum_{i=1}^{g} t_{i}\left(t_{i}-1\right)\left(2 t_{i}+5\right)}{18}
$$

where $t_{i}$ denotes the number of ties to extent $i$ and $g$ is the number of tied groups. The summation term in the numerator is used only if the data series contains tied values [17].

\subsection{Standard Test Statistic $Z_{s}$}

The standard test statistic Zs is calculated as follows:

$$
Z_{s}=\left\{\begin{array}{l}
\frac{s-1}{\sigma} \text { for } S>0 \\
0 \text { for } S=0 \\
\frac{S+1}{\sigma} \text { for } S<0
\end{array}\right.
$$

The test statistic $Z_{s}$ is used as a measure of significance of trend.
In fact, this test statistic is used to test the null hypothesis $\mathrm{H}_{0}$. If $\left|Z_{s}\right|$ is greater than $Z_{\alpha / 2}$, where $\alpha$ represents the chosen significance level (e.g.: $5 \%$ with $Z 0.025=1.96$ ) then the null hypothesis is invalid implying that the trend is significant [17].

\subsection{Sources of Error}

No information available about the number of precipitation gauges and temperature sensors used in each sub-basin to record precipitation and temperature data. Also, the exact location of these gauges and sensors is unknown. The lack of uniformity in precipitation gauges and temperature sensors can influence the quality of recorded data [18]. It is mentioned on the website of data center of Pakistan Meteorological Department (PMD) that probability of collecting 100\% correct data is very low due to data transmission problems which occur while the data is transmitted form stations to the data center.

\section{Analysis \& Results}

The value of $Z_{s}$ for all five substations is shown in the Table-2. Now Table 2 shows the value of $Z_{s}$ calculated for all twelve months for all five stations respectively, using mann-kendall

\begin{tabular}{|c|c|c|c|c|c|c|c|c|c|c|c|c|c|}
\hline Station & Statistics & January & February & March & April & May & June & July & August & September & Dctober & November & December \\
\hline \multirow{4}{*}{ Astor } & $z$ & 0.85 & 1.42 & 2.25 & 1.63 & 1.73 & 3.24 & 0.82 & 0.97 & -1.98 & 1.48 & 0.81 & -0.14 \\
\hline & $\begin{array}{l}\text { Critical Z } \\
\text { Yalue. } \\
\alpha=5 \%\end{array}$ & $\neq 1.96$ & \pm 1.96 & \pm 1.96 & \pm 1.96 & $=1.96$ & \pm 1.96 & \pm 1.96 & $=1.96$ & \pm 1.96 & $=1.96$ & $=1.96$ & \pm 1.96 \\
\hline & \begin{tabular}{|l|} 
H. \\
hypothesis
\end{tabular} & Accept & Accept & Reject & Accept & Accept & Reject & Accept & Accept & Reject & Accept & Accept & Accept \\
\hline & $\begin{array}{l}\text { Trend. } \\
\text { I }\end{array}$ & No & No & Yes[*] & No & No & Yes[*] & No & No & Yes[-] & No & No & No \\
\hline \multirow{4}{*}{ Drosh } & $z$ & 0.00 & -1.36 & 1.55 & -0.64 & 0.45 & -1.20 & -2.25 & -1.96 & -2.56 & 0.00 & -2.62 & -1.36 \\
\hline & $\begin{array}{l}\text { Critical Z } \\
\text { Yalue. } \\
\alpha=5 \%\end{array}$ & $=1.96$ & $=1.96$ & $=1.96$ & $\$ 1.96$ & $\$ 1.96$ & \pm 1.96 & \pm 1.96 & $=1.96$ & $\neq 1.96$ & $=1.96$ & $=1.96$ & $=1.96$ \\
\hline & $\begin{array}{l}\text { H. } \\
\text { hypothesis }\end{array}$ & Accept & Accept & Accept & Accept & Accept & Accept & Reject & Accept & Reject & Accept & Reject & Accept \\
\hline & \begin{tabular}{|l} 
Trend. \\
.
\end{tabular} & No & No & No & No & No & No & Yes[-] & No & Yes[-] & No & Yes[-] & No \\
\hline \multirow{4}{*}{ Gilgit } & $z$ & 0.82 & 1.34 & 2.74 & 2.17 & 1.49 & 2.00 & -0.49 & 0.00 & -2.23 & 2.72 & 2.06 & 0.08 \\
\hline & $\begin{array}{l}\text { Critical Z } \\
\text { Yalue. } \\
\alpha=5 \%\end{array}$ & \pm 1.96 & $\leq 1.96$ & \pm 1.96 & \pm 1.96 & \pm 1.96 & \pm 1.96 & \pm 1.96 & \pm 1.96 & \pm 1.96 & $=1.96$ & \pm 1.96 & \pm 1.96 \\
\hline & $\begin{array}{l}\text { H. } \\
\text { hypothesis }\end{array}$ & Accept & Accept & Reject & Reject & Accept & Reject & Accept & Accept & Reject & Reject & Reject & Accept \\
\hline & $\begin{array}{l}\text { Trend. } \\
\text { : }\end{array}$ & No & No & Yes[*] & Yes[*] & No & Yes[*] & No & No & Yes[-] & Yes[*] & Yes[*] & No \\
\hline \multirow{4}{*}{ Gupis } & $z$ & 0.54 & 0.47 & 2.27 & 0.89 & 1.22 & 1.22 & -0.64 & -1.20 & -1.53 & 2.44 & 0.21 & 0.29 \\
\hline & $\begin{array}{l}\text { Critical Z } \\
\text { Yalue. } \\
\alpha=5 \%\end{array}$ & $\neq 1.96$ & $\neq 1.96$ & $\neq 1.96$ & $\neq 1.96$ & $\neq 1.96$ & $\neq 1.96$ & \pm 1.96 & $\leq 1.96$ & $\neq 1.96$ & $\neq 1.96$ & $\neq 1.96$ & \pm 1.96 \\
\hline & $\begin{array}{l}\text { H. } \\
\text { hypothesis }\end{array}$ & Accept & Accept & Reject & Accept & Accept & Accept & Accept & Accept & Accept & Reject & Accept & Accept \\
\hline & 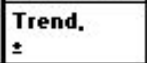 & No & No & Yes[*] & No & No & No & No & No & No & Yes[*] & No & No \\
\hline \multirow{4}{*}{ Skurdu } & $z$ & 0.25 & 0.49 & 0.99 & 0.23 & 0.64 & -0.12 & -1.40 & -1.09 & -2.97 & -0.56 & -1.96 & -1.57 \\
\hline & $\begin{array}{l}\text { Critical Z } \\
\text { Yalue. } \\
\alpha=5 \%\end{array}$ & $\neq 1.96$ & $\neq 1.96$ & $\neq 1.96$ & \pm 1.96 & $\neq 1.96$ & $\neq 1.96$ & \pm 1.96 & $\neq 1.96$ & \pm 1.96 & $\neq 1.96$ & $\neq 1.96$ & \pm 1.96 \\
\hline & \begin{tabular}{|l|} 
H. \\
hypothesis
\end{tabular} & Accept & Accept & Accept & Accept & Accept & Accept & Accept & Accept & Reject & Accept & Reject & Accept \\
\hline & \begin{tabular}{|l} 
Trend. \\
.
\end{tabular} & No & No & No & No & No & No & No & No & Yes[-] & No & Yes[-] & No \\
\hline
\end{tabular}
trend test.

Table 2: Tabulated value of $Z=Z_{\text {s }}$ against $Z_{\mathrm{cr}}$ 


\subsection{Tabulated Result}

This value of $Z_{\mathrm{s}}$ is than compared with the value of critical $Z$ or $Z_{\text {cr }}$ for the significance level of $5 \%$, which comes out to be \pm 1.96 .

- If the value of $Z_{\mathrm{s}}$ is greater than +1.96 than this will imply that there is an increasing trend.

- If the value of $Z_{\mathrm{s}}$ is smaller than -1.96 than this will imply the presence of a decreasing trend.

- For all values between +1.96 and -1.96 ; it is considered that there is no significant trend. Neither increasing nor decreasing.

- For values of $Z_{\mathrm{s}}$ greater than +1.96 and smaller than -1.96 the null hypotheis is rejected.

- For all values of $Z_{s}$ in between \pm 1.96 , null hypothesis is accepted.

When the null hypothesis is rejected, trend is accepted and similarly if null hypothesis is accepted than trend is rejected. Using this approach Table 2 shows 3 accepted trends in March, June and September for Astore station.

\subsection{Graphical Representation of Results}

\section{1- Astore Standard Test Statistic Graph}

The results from the trend analysis of mean monthly temperature data of Astore station shows that for Astore station, the Zs test statistic plotted in Figure 2 for the month of March $(Z s=2.25)$ and for the month of June $\left(Z_{s}=3.24\right)$ is higher than the critical value of 1.96 at $(\alpha=5 \%$ or 0.05$)$ significance level.

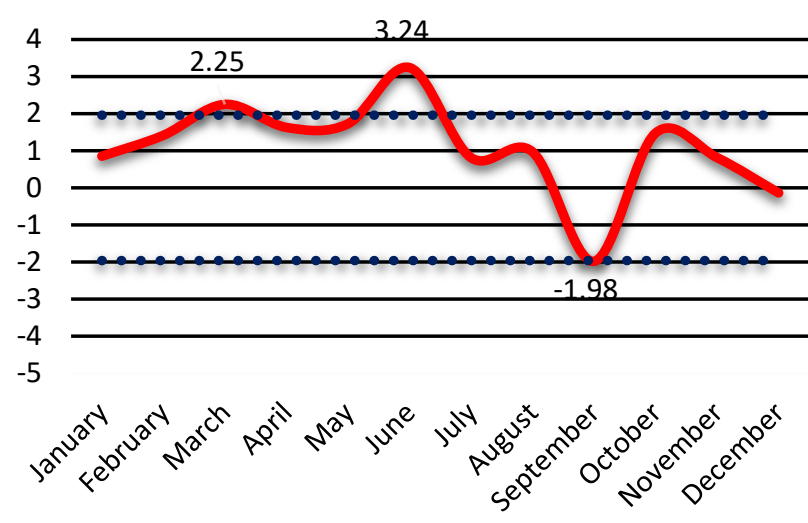

z Value .... Critival Value .... Critical Value

Figure 2: Graph plotted for Astore station between $\mathrm{Zs}$ calculated and $\mathrm{Z}$ critical at Significance level $\alpha=0.05$

This shows increasing trend which indicates higher temperature during summer and early arrival of summer season. The results also show the $\mathrm{Zs}$ test statistic for month of September $\left(\mathrm{Zs}_{\mathrm{s}}=\right.$ 1.98).

\section{2- Drosh Standard Test Statistic Graph}

The results from the trend analysis of mean monthly temperature data of Drosh station shows no considerable variation in trend for summer season. Whereas the results show the $Z_{s}$ test statistic plotted in Figure 3 for month of July $\left(Z_{s}=\right.$ -
2.25), September $\left(Z_{s}=-2.56\right)$ and November $\left(Z_{s}=-2.62\right)$ there is a considerable decreasing trend which indicates lowering of temperature and early arrival of winter season.

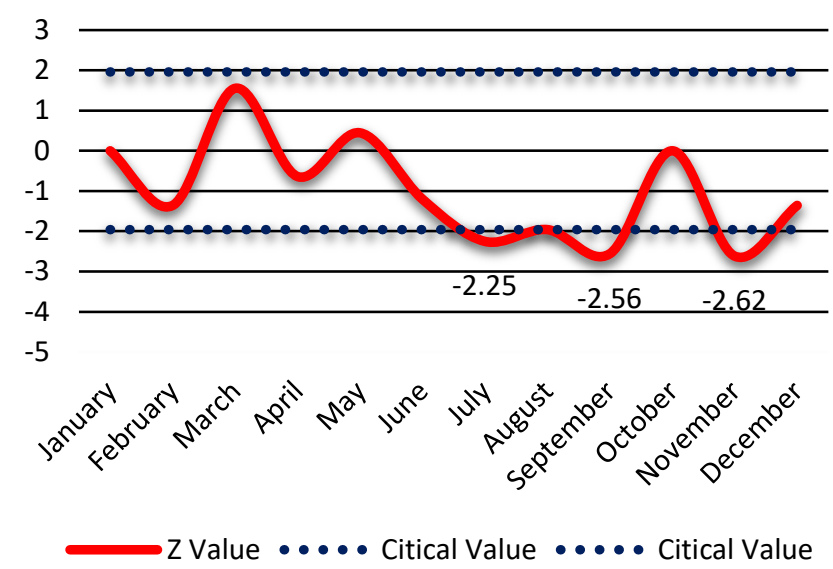

Figure 3: Graph plotted for Drosh station between Zs calculated and $\mathrm{Z}$ critical at Significance level $\alpha=0.05$

\section{3- Gilgit Standard Test Statistic Graph}

The results from trend analysis of mean monthly temperature data of Gilgit station show that for Gilgit station, the $Z_{\mathrm{s}}$ test statistic plotted in Figure 4 for the month of March $\left(Z_{s}=2.74\right)$, April $\left(Z_{s}=2.17\right)$ and June $\left(Z_{s}=2\right)$ is higher than the critical value of 1.96 at $(\alpha=5 \%$ or 0.05$)$ significance level. This shows increasing trend which indicates higher temperature during and early arrival of summer season.

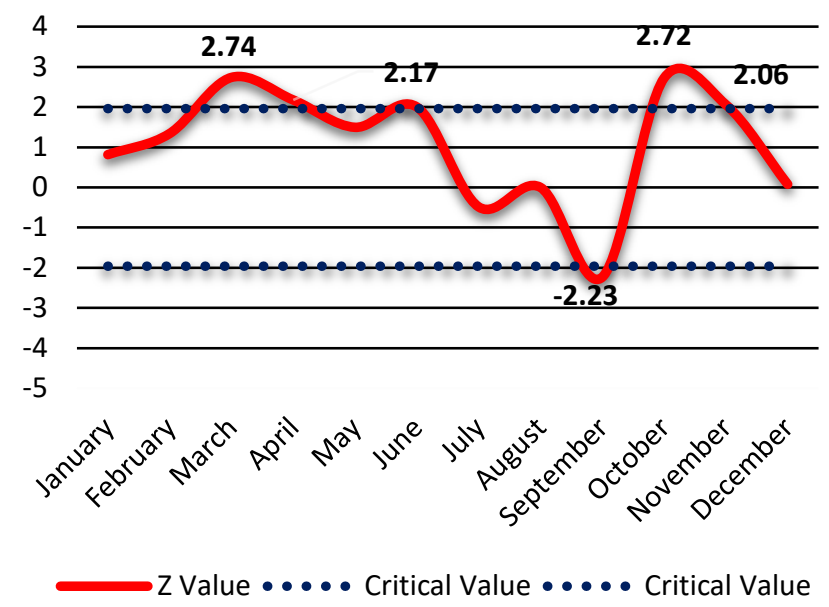

Figure 4: Graph plotted for Gilgit station between Zs calculated and $Z$ critical at Significance level $\alpha=0.05$

The results also show the $Z_{s}$ test statistic for month of September $\left(Z_{s}=-2.23\right)$ there is a considerable decreasing trend which indicates lowering of temperature and early arrival of winter season. But the months of October $\left(Z_{\mathrm{s}}=2.72\right)$ and November $\left(Z_{s}=2.06\right)$ show complex increasing trends (may be due to errors in data observation) which indicate increase of temperature during winter season.

\section{4- Gupiz Standard Test Statistic Graph}

The results from the trend analysis of mean monthly temperature data of Gupiz station show that for Gupiz station, 
the $Z_{s}$ test statistic plotted in Figure 5 for the month of March $\left(Z_{s}=2.27\right)$ is higher than the critical value of 1.96 at $(\alpha=5 \%$ or $0.05)$ significance level. Which shows increasing trend which indicates higher temperature during and early arrival of summer season. But the months of October $\left(Z_{s}=2.44\right)$ show unexpected increasing trends which indicate increase of temperature during winter season.

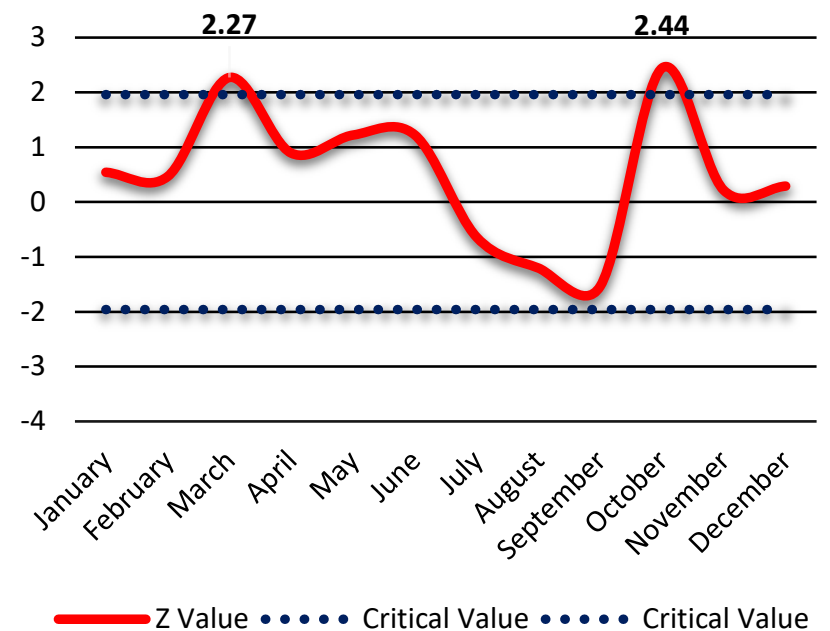

Figure 5: Graph plotted for Gupiz station between Zs calculated and $\mathrm{Z}$ critical at Significance level $\alpha=0.05$

\section{5- Skardu Standard Test Statistic Graph}

The results from the trend analysis of mean monthly temperature data of Skardu station show that for Drosh station, the $Z_{\text {s }}$ statistic plotted in Figure 6 shows no considerable variation in trend for summer season. Whereas the results show the $Z_{s}$ test statistic for month of September $\left(Z_{s}=-2.97\right)$, November $\left(Z_{s}=-1.96\right)$ there is a considerable decreasing trend which indicates lowering of temperature and early arrival of winter season.

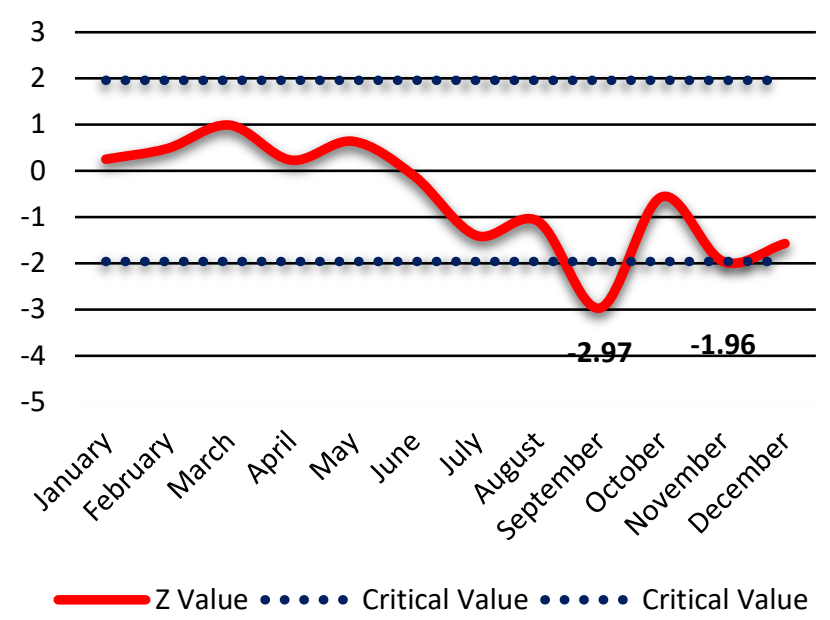

Figure 6: Graph plotted for Skardu station between Zs calculated and $Z$ critical at Significance level $\alpha=0.05$

\subsection{Seasonal Comparison}

1- For Winter Season plotted in Figure 6:

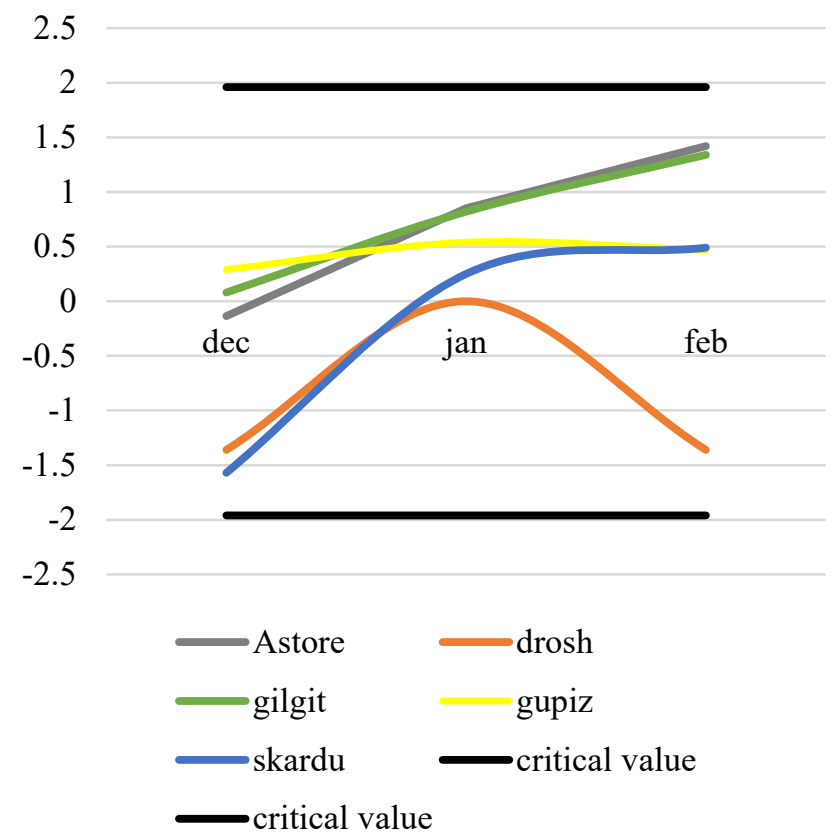

Figure 7: No increasing or decreasing trend in winter

\section{2- For Spring Season plotted in Figure 7:}

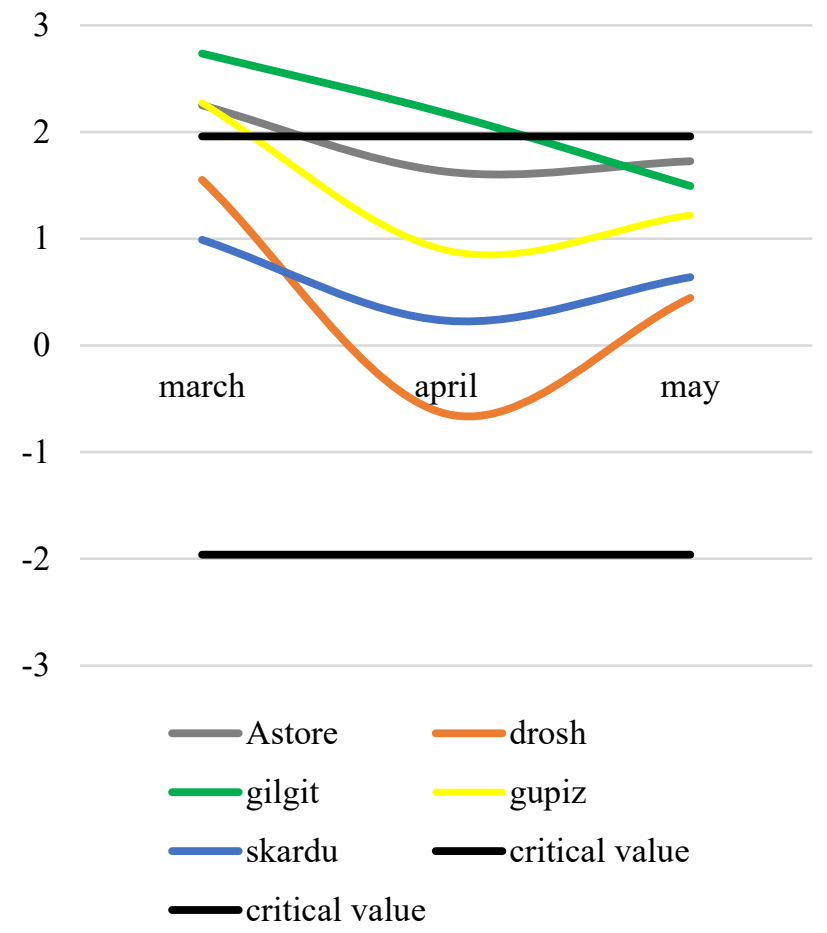

Figure 8: Increasing trend detected in Gupiz, Astore \& Gilgit (Temperature starts increasing from March) 


\section{3- For Summer Season plotted in Figure 8:}

4

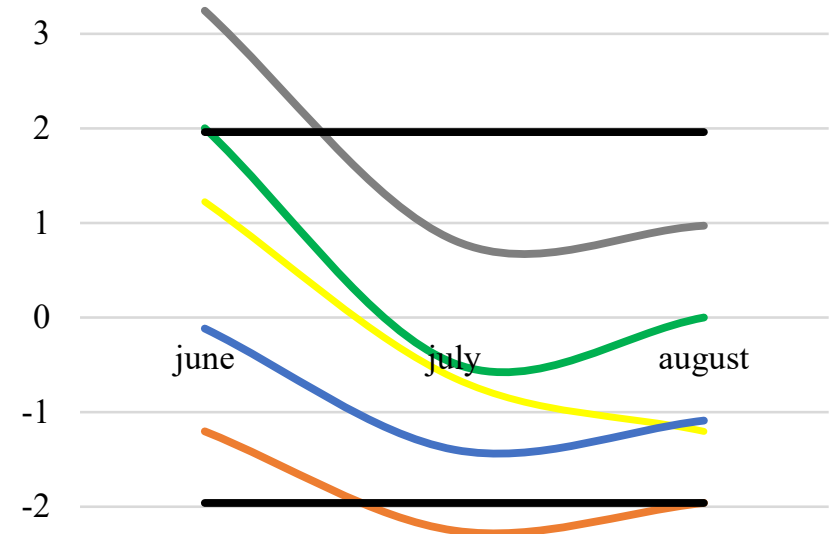

$-3$

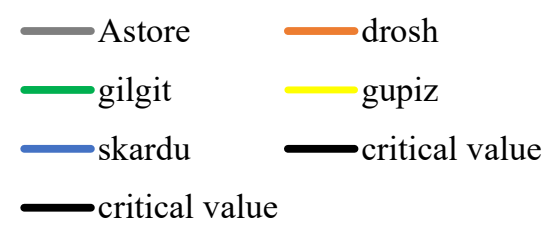

Figure 9: Increasing trend detected in Astore and Gilgit for June and abnormal decreasing trend in Drosh for July

4- For Autumn Season plotted in Figure 9:

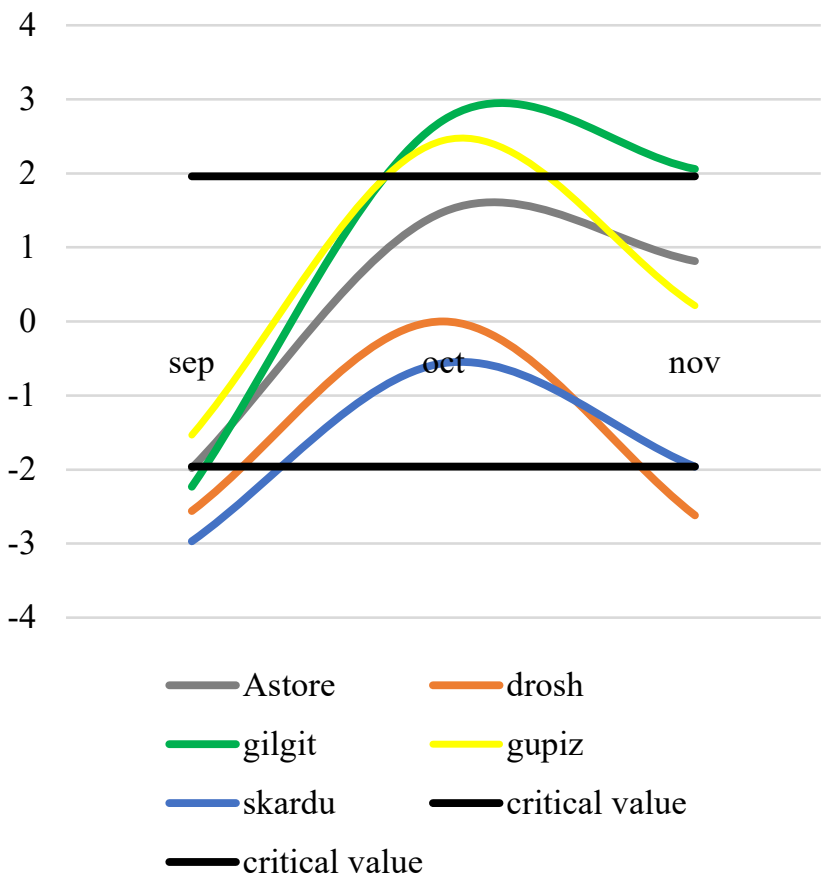

Figure 10: Decreasing trends in Skardu, Drosh \& Gilgit for September; Increasing trend in Gupiz \& Gilgit for October

\section{Conclusions \& Recommendations}

\subsection{Conclusions}

The main aim of this study was to detect trends in mean monthly, seasonal and annual temperature resolution in Upper Indus River Basin (UIRB), KP, Pakistan for five selected meteorological stations using Mann-Kendall Trend Test. The study revealed the following findings:

i. A generalized increase was noted in mean monthly temperature at most time scales and particularly in winter, pre-monsoon, and at the annual resolution. The maximum increase in temperature was found in March and in the premonsoon season.

ii. There were numbers of locations showing significant increasing trends (Positive) than decreasing trends (Negative) in different seasons.

iii. A generalized cooling was observed in mean monthly temperature in study region in the monsoon, post-monsoon and on the annual time scale. While mean monthly temperature increased significantly in these areas in winter, pre-monsoon, post-monsoon and on an annual basis.

iv. Mean monthly temperature increased abruptly from February to May (especially in March); July, August, and October; winter and the pre-monsoon season; and at the annual resolution. Rate of increase in mean monthly temperature during pre-monsoon period was found higher as compared to the rate of decrease in mean monthly temperature during post-monsoon period.

v. A significant increasing trend in mean monthly temperature was noted at Astore, Gilgit and Gupiz during the month of March and a considerably decreasing trend in mean monthly temperature for the Astore, Drosh, Gilgit and Skardu stations in the month of September.

vi. Gilgit and Gupiz showed unexpected increasing trend in mean monthly temperatures in the month of October.

vii. Temperature starts increasing in March and stays elevated till the onset of winter and starts rising again in October thus expansion of summer season and prolonged glacial melting.

\subsection{Recommendations}

1- Control Global Warming

All preventive measures for control of global warming should be given serious thought and standard operating procedures should be implemented. Such as:

- Deforestation should be discouraged.

- Use of fossil fuels should be minimized. etc.

2- Store Excess Water

- Preparations should be made to increase storage capacity of reservoirs.

- Building new reservoirs must be prior consideration.

3- Reforms in Agriculture

Time of harvesting of summer crops and time of sowing of winter crops should be managed. 


\section{4- Flood Control}

Studies should be carried out for mapping of endangered settlements in flood prone areas.

\section{5- Further Research}

The scope of this study was curbed to only five sub basins of Upper Indus Basin (UIB) and to only 30 years of data. More comprehensive studies should be carried out using data of more than 30 years and by increasing the area of interest (AOI) i.e., number of sub basins of Upper Indus Basin (UIB). Large scale studies will give a comprehensible and broader image of the temp-erature trends in the Upper Indus Basin (UIB). Furthermore the studies conducted for temperature trends should be compared with the studies conducted for other climatological parameters such as precipitation and humidity to investigate the climatic patterns in depth.

\section{Acknowledgements}

All praise be to Almighty Allah and much gratitude to the parents and families of authors for their support and prayers that made their work possible. The authors are grateful to the $D r$. Ghulam Rasool (D.G) and Miss. Ghazala Naheed (Meteorologist) of the Pakistan Meteorological Department (PMD), Islamabad, for providing relevant information for this study. The present study was approved and encouraged by the members of Project Evaluation Committee at University of Engineering \& Technology Peshawar, Bannu Campus, KP, Pakistan.

\section{References}

[1] Fourth Assessment Report (AR4), Climate Change 2007, Intergovernmental Panel on Climate Change, Cambridge University Press, Cambridge, IPCC (2007).

[2] Qamar-uz-Zaman Chaudhry, Arif Mahmood, Ghulam Rasul, and Muhammad Afzaal. Technical Report No. PMD 22/2009, Climate Change Indicators of Pakistan, Pakistan Meteorological Department, Islamabad, PMD (2009).

[3] Yue, S., Pilon, P. \& Caradias, G., "Power of the Mann-Kendall and Spearman's rho tests, for detecting monotonic trends in hydrological series" J. Hydrology, 259: 254-271 (2002).

[4] Pakistan's Climate Change Policies and Actions, Task Force on Climate Change Planning Commission, Planning and Development Division Government of Pakistan, Islamabad, TFCC (2009).

[5] D. E. Parker and L. V. Alexander, "Global and Regional Climate in 2001," Weather, 57(9): 328-340 (2002).

[6] Kuti, I. Abayomi, I. Murtala Animashaun, Babatunde Olawale, and Suleiman Abdullahi. "Trend Analysis of Hydro-meteorological Data for River Kaduna at Shiroro Dam Site, Niger State Nigeria", J. Sci. Res. Rep., 8(5): 1-12 (2015).

[7] Nam, Won-Ho, Eun-Mi Hong, and Guillermo A. Baigorria. "How climate change has affected the spatio-temporal patterns of precipitation and temperature at various time scales in North Korea" International Journal of Climatology, 36(2): $722-734$ (2016).

[8] Venable, Niah BH, Steven R. Fassnacht, and Alyssa D. Hendricks. "Spatial Changes in Climate across Mongolia." Building Resilience of Mongolian Rangelands 73: (2015).

[9] Mahmood, Rashid, Shaofeng Jia, and Mukand S. Babel. "Potential impacts of climate change on water resources in the Kunhar River basin, Pakistan."Water 8(1): 23 (2016).

[10] Chattopadhyay, Somsubhra, and Dwayne R. Edwards. "Long-Term Trend Analysis of Precipitation and Air Temperature for Kentucky, United States." Climate, 4(1): 10(2016).
[11] Khan, Khalida, Muhammad Yaseen, Yasir Latif, and M. Nabi. "Detection of river flow trends and variability analysis of Upper Indus Basin, Pakistan."Sci. Int. (Lahore) 27(2): 1261-1270 (2015).

[12] Pamela S. Adams, US Department of the Interior Bureau of Reclamation, Colorado (2016).

[13] "Flood early warning system manual for Indus Basin". National Engineering Services Pakistan (NESPAK), Lahore, 425(1997).

[14] http://www.cwc.nic.in/regionaloffice/chandigarh/images/basin.jpg

[15] Onoz, B., Bayazit, M., The Power of Statistical Tests for Trend Detection (2012).

[16] Drapela, K., Drapelova, I., "Application of Mann-Kendall test and the Sen's slope estimates for trend detection in deposition data from Bílý Kříž (Beskydy Mts., the Czech Republic) 1997-2010”. Beskdy Mendel University in Brno 4(2): 133-146 (2011).

[17] Motiee H., McBean E., An Assessment of Long Term Trends in Hydrologic Components and Implications for Water Levels in Lake Superior. Hydrology Research 40(6): 564-579 (2009).

[18] National Climatic Data Center, NCDC Website Privacy Policy, http://www.ncdc.noaa.gov/oa/about/privacystatement.html\#disclaimer. Date Accessed 07/15/2012. 